\title{
Unhappy End of 'Happy Balloons': Subacute Combined Degeneration Caused by Nitrous Oxide Gas
}

\author{
Ye-Ji Kwon \\ Jeong Hwa Rho \\ Jihyeon Hwang \\ Seol-Hee Baek \\ Department of Neurology, \\ Korea University Medical Center, \\ Korea University College of Medicine, \\ Seoul, Korea
}

\author{
Received July 24, 2018 \\ Revised August 6, 2018 \\ Accepted August 9, 2018

\section{Correspondence} \\ Seol-Hee Baek, MD \\ Department of Neurology, \\ Korea University Medical Center, \\ Korea University College of Medicine, \\ 73 Inchon-ro, Seongbuk-gu, \\ Seoul 02841, Korea \\ Tel +82-2-920-6825 \\ Fax $+82-2-926-5347$ \\ E-mailvvirgo3318@gmail.com
}

Dear Editor,

Subacute combined degeneration (SCD) is a potentially reversible and treatable myelopathy that primarily affects the dorsolateral columns of the spinal cord. It is the well-documented complication of cobalamin (vitamin $\mathrm{B}_{12}$ ) deficiency, which is often observed in patients who are suffering from pernicious anemia, various conditions leading to malnutrition, tropical sprue, or HIV infection. ${ }^{1}$ Nitrous oxide $\left(\mathrm{N}_{2} \mathrm{O}\right)$ exerts neurotoxic effects by interfering with the bioavailability of cobalamin, but $\mathrm{N}_{2} \mathrm{O}$ as an etiology of the condition is not well known and often underestimated. Herein we report a case series of two patients diagnosed with SCD caused by massive $\mathrm{N}_{2} \mathrm{O}$ inhalation.

Patient A was a 22-year-old woman who presented with progressive paresthesia in her legs and hands, and unsteady gait that had first appeared about 2 months previously. She was currently taking medication for depression. She had been diagnosed and treated for a pulmonary embolism 1 month previously. In addition, she was injected intramuscularly with single high-dose supplementation of cobalamin for incidentally found cobalamin deficiency. Further questioning revealed a habit of inhaling 'happy balloons' more than 100 times for the past 2 months. A neurological examination revealed decreased tactile and vibratory sensations of the legs, dysmetria in heel-to-shin tests on both sides, a positive Romberg's sign, and bilateral weakness of both lower extremities (each with Medical Research Council grade III).

Patient B was a 33-year-old man who presented with progressive symmetrical numbness in his legs, imbalance, and difficulty walking. He had a history of a diagnosis of reflux esophagitis with seropositive for Helicobacter pylori (H. pylori), but this was never treated. Further questioning revealed a daily habit of inhaling up to $5 \mathrm{~L}$ of 'laughing gas' for the past 6 months. A neurological examination revealed weakness in both upper and lower extremities, decreased vibration and proprioception sensations, bilateral hyporeflexia, sensory ataxia, and a positive Romberg's sign.

Both patients A and B had no cognitive impairment or psychiatric problems, with the exception of patient A having suffered from depression several years previously. The initial laboratory tests revealed that both patients $\mathrm{A}$ and $\mathrm{B}$ had elevated mean corpuscular volumes and low cobalamin levels. The folate level was normal in both patients, who were negative for antibodies to human immunodeficiency virus and neurosyphilis. Whole-spine MRI revealed increased T2-weighted signals in the dorsal columns with a characteristic inverted V sign' (Fig. 1A and C). A nerve conduction study showed axonal motor polyneuropathy (Fig. 1B and D), and somatosensory evoked potentials suggested a lesion in somatosensory pathways between the upper cervical cord and somatosensory cortex.

Both patients were diagnosed with SCD of the spinal cord induced by $\mathrm{N}_{2} \mathrm{O}$ consumption, and they were treated with daily intramuscular cobalamin $(1 \mathrm{mg})$ injections for 2 weeks followed by oral medication. This cobalamin treatment combined with the removal of the offending agent resulted in both patients showing a gradual neurological improvement with

(a) This is an Open Access article distributed under the terms of the Creative Commons Attribution Non-Commercial License (https://creativecommons.org/licenses/by-nc/4.0) which permits unrestricted non-commercial use, distribution, and reproduction in any medium, provided the original work is properly cited. 


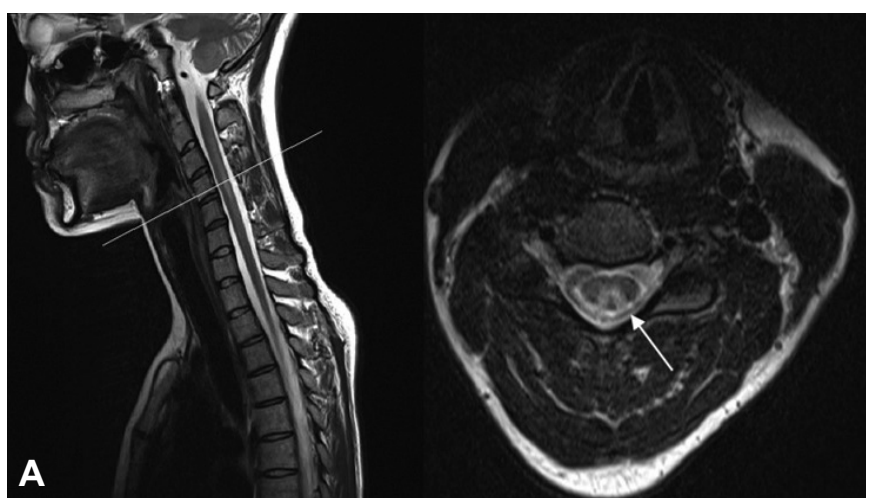

\begin{tabular}{|c|c|c|c|c|c|c|c|c|}
\hline \multirow{2}{*}{$\begin{array}{l}\text { Nerve } \\
\text { (motor) }\end{array}$} & \multirow{2}{*}{$\begin{array}{l}\text { Stimulation } \\
\text { site }\end{array}$} & \multirow{2}{*}{$\begin{array}{l}\text { Recording } \\
\text { site }\end{array}$} & \multicolumn{2}{|c|}{$\begin{array}{l}\text { Distal latency } \\
\text { (ms) }\end{array}$} & \multicolumn{2}{|c|}{$\begin{array}{l}\text { Amplitude } \\
\text { (mV) }\end{array}$} & \multicolumn{2}{|c|}{$\begin{array}{l}\text { Conduction } \\
\text { velocity }(\mathrm{m} / \mathrm{s})\end{array}$} \\
\hline & & & $\mathrm{RT}$ & LT & RT & LT & RT & $\mathrm{LT}$ \\
\hline \multirow[t]{3}{*}{ Median } & Wrist & APB & 2.7 & ND & 8.2 & ND & & \\
\hline & Elbow & & 7.4 & ND & 7.8 & ND & 52 & \\
\hline & Axilla & & 8.9 & ND & 7.7 & ND & 55 & \\
\hline \multirow[t]{3}{*}{ Ulnar } & Wrist & ADM & 1.9 & ND & 15.5 & ND & & \\
\hline & Elbow & & 6.5 & ND & 12.1 & ND & 56 & \\
\hline & Axilla & & 8.1 & ND & 11.5 & ND & 62 & \\
\hline \multirow[t]{3}{*}{ Peroneal } & Ankle & EDB & $6.4^{*}$ & 4.4 & $1.0^{*}$ & $1.3^{*}$ & & \\
\hline & $\mathrm{FH}$ & & 14.3 & 14.5 & $0.8^{*}$ & $0.7^{*}$ & 42 & 33 \\
\hline & $\mathrm{FH}$ & TA & 7.5 & 6.0 & 3.0 & 3.8 & & \\
\hline \multirow{2}{*}{$\begin{array}{l}\text { Tibial } \\
\mathbf{B}\end{array}$} & Ankle & $\mathrm{AH}$ & $5.8^{*}$ & $5.6^{*}$ & $2.3^{*}$ & 7.1 & & \\
\hline & PF & & 14.9 & $14.9^{*}$ & $2.3^{*}$ & 4.5 & 44 & 43 \\
\hline
\end{tabular}

Patient B

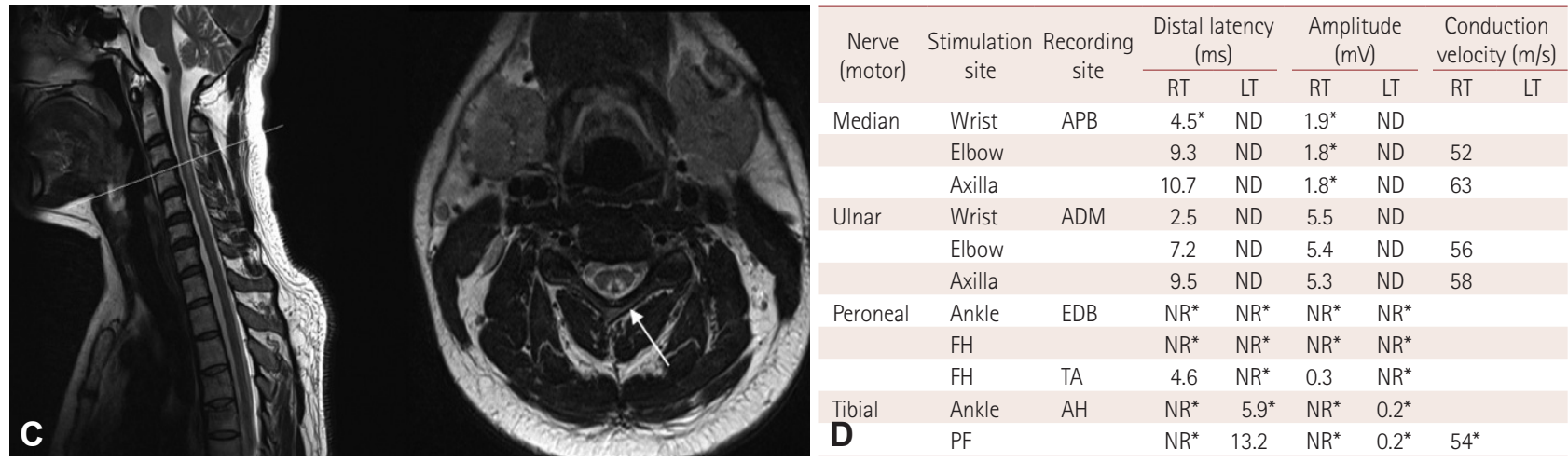

Fig. 1. Findings of MRI and nerve conduction studies in both patients. Sagittal and axial T2-weighted images exhibited hyperintensities in the cervical cord region with an 'inverted $\mathrm{V}$ sign' (arrows) typical of subacute combined degeneration ( $\mathrm{A}$ and $\mathrm{C}$ ). Nerve conduction studies revealed axonal motor neuropathy (B and D). *Abnormal values. ADM: abductor digiti minimi muscle, AH: abductor hallucis brevis muscle, APB: abductor pollicis brevis muscle, EDB: extensor digitorum brevis muscle, FH: fibular head, LT: left, ND: not done, NR: no response, PF: popliteal fossa, RT: right, TA: tibialis anterior muscle.

rehabilitation.

Cobalamin is an essential cofactor for cellular reactions, with it supporting methionine synthetase and further participating in the synthesis of myelin sheath. ${ }^{2}$ Low cobalamin levels may result in various neurological manifestations such as peripheral neuropathy, myelopathy with dorsal column dysfunction, and encephalopathy with cognitive decline. ${ }^{3}$ There have been many reports of early diagnosis and rapid treatment being crucial to a favorable outcome.

$\mathrm{N}_{2} \mathrm{O}$ was originally used as an inhalational anesthetic agent. However, its recreational consumption is increasing due to its easy accessibility and low cost. The consumption of a large amount of $\mathrm{N}_{2} \mathrm{O}$ accelerates the irreversible oxidation of the cobalt ion of cobalamin, which results in the inactivation of the cofactor required for myelin formation. ${ }^{1-3}$ Any patients with preexisting conditions for SCD_-anorexia nervosa and $H$. pylori in our two cases-or a chronically low cobalamin level may be more vulnerable to the adverse effects of $\mathrm{N}_{2} \mathrm{O} .{ }^{4}$ It is paramount that clinicians inquire about and perform screening for $\mathrm{N}_{2} \mathrm{O}$ abuse if there is no clear etiology of SCD, especially in young patients without predisposing conditions.

\section{Conflicts of Interest}

The authors have no financial conflicts of interest.

\section{REFERENCES}

1. Green R, Kinsella LJ. Current concepts in the diagnosis of cobalamin deficiency. Neurology 1995;45:1435-1440.

2. Jordan JT, Weiser J, Van Ness PC. Unrecognized cobalamin deficiency, nitrous oxide, and reversible subacute combined degeneration. Neurol Clin Pract 2014;4:358-361.

3. Flippo TS, Holder WD Jr. Neurologic degeneration associated with nitrous oxide anesthesia in patients with vitamin B12 deficiency. Arch Surg 1993;128:1391-1395.

4. Schilling RF. Is nitrous oxide a dangerous anesthetic for vitamin B12deficient subjects? JAMA 1986;255:1605-1606. 